Check for updates

Cite this: RSC Adv., 2018, 8, 5897

\section{Improved performance and stability of perovskite solar cells with bilayer electron-transporting layers}

\begin{abstract}
Tingting Jiang ${ }^{a}$ and Weifei Fu (D) *b
Zinc oxide nanoparticles (NPs) are very promising in replacing the phenyl- $\mathrm{C}_{61}$-butyric acid methyl ester $\left(\mathrm{PC}_{61} \mathrm{BM}\right)$ as electron-transporting materials due to the high carrier mobilities, superior stability, low cost and solution processability at low temperatures. The perovskite/ZnO NPs heterojunction has also demonstrated much better stability than perovskite/PC ${ }_{61} \mathrm{BM}$, however it shows lower power conversion efficiency (PCE) compared to the state-of-art devices based on perovskite/PCBM heterojunction. Here, we demonstrated that the insufficient charge transfer from methylammonium lead iodide $\left(\mathrm{MAPb}_{3}\right)$ to ZnO NPs and significant interface trap-states lead to the poor performance and severe hysteresis of PSC with $\mathrm{MAPb}_{3} / \mathrm{ZnO}$ NPs heterojunction. When $\mathrm{PC}_{61} \mathrm{BM} / \mathrm{ZnO}$ NPs bilayer electron transporting layers (ETLs) were used with a device structure of ITO/poly(bis(4-phenyl)(2,4,6-trimethylphenyl)amine) (PTAA)/ $\mathrm{MAPb}_{3} / \mathrm{PC}_{61} \mathrm{BM} / \mathrm{ZnO} \mathrm{NPs} / \mathrm{Al}$, which can combine the advantages of efficient charge transfer from $\mathrm{MAPb}_{3}$ to $\mathrm{PC}_{61} \mathrm{BM}$ and excellent blocking ability of ZnO NPs against oxygen, water and electrodes, highly efficient PSCs with PCE as high as $17.2 \%$ can be achieved with decent stability.
\end{abstract}

Received 9th January 2018 Accepted 1st February 2018

DOI: $10.1039 / \mathrm{c} 8 \mathrm{ra00248g}$

rsc.li/rsc-advances are widely studied. Among them, metal oxide nanoparticles (NPs) are very promising in replacing the organic counterparts due to the high carrier mobilities, superior stability, low cost and solution processability at low temperatures. ${ }^{16,31,33}$

The perovskite/ZnO NPs heterojunction has been demonstrated much better stability than perovskite/PCBM, ${ }^{23}$ however it shows lower PCE compared to the state-of-art devices based on perovskite/PCBM heterojunction. ${ }^{36-38}$ Thus in this paper, we systematically studied the charge transfer and recombination at $\mathrm{CH}_{3} \mathrm{NH}_{3} \mathrm{PbI}_{3}\left(\mathrm{MAPbI}_{3}\right)$ and $\mathrm{ZnO}$ NPs or $\mathrm{PC}_{61} \mathrm{BM}$ interfaces and tried to fabricate devices with high PCE and super stability simultaneously. We demonstrated that insufficient charge transfer from $\mathrm{MAPbI}_{3}$ to $\mathrm{ZnO}$ NPs and significant interface trap-states lead to the poor performance and severe hysteresis of PSCs based on $\mathrm{MAPbI}_{3} / \mathrm{ZnO}$ NPs heterojunction, while the devices based on $\mathrm{MAPbI}_{3} / \mathrm{PC}_{61} \mathrm{BM}$ show high PCE and negligible hysteresis due to the efficient charge transfer from $\mathrm{MAPbI}_{3}$ to $\mathrm{PC}_{61} \mathrm{BM}$ and less recombination at the interface. On the other hand, the $\mathrm{MAPbI}_{3} / \mathrm{ZnO}$ NPs devices show excellent stability in air because of the excellent capping ability of $\mathrm{ZnO}$ NPs while the stability of $\mathrm{MAPbI}_{3} / \mathrm{PC}_{61} \mathrm{BM}$ devices is very poor. Thus, we fabricated the PSCs with bilayer electron-transporting layers (ETLs) with the device structure of ITO/poly(bis(4-phenyl)(2,4,6-trimethylphenyl)amine) (PTAA)/ $\mathrm{MAPbI}_{3} / \mathrm{PC}_{61} \mathrm{BM} / \mathrm{ZnO} \mathrm{NPs} / \mathrm{Al}$, trying to combine the advantages of efficient charge extraction ability of $\mathrm{PC}_{61} \mathrm{BM}$ and excellent blocking ability of ZnO NPs against oxygen, water and electrode, and finally device with PCE as high as $17.2 \%$ was achieved with decent stability.
${ }^{a}$ The State Key Laboratory of Refractories and Metallurgy, College of Materials and Metallurgy, Wuhan University of Science and Technology, Wuhan 430081, P. R. China ${ }^{b}$ State Key Laboratory of Silicon Materials, MOE Key Laboratory of Macromolecular Synthesis and Functionalization, Department of Polymer Science and Engineering, Zhejiang University, Hangzhou 310027, P. R. China. E-mail: zjufwf@zju.edu.cn 


\section{Experimental}

\subsection{Materials}

Zinc acetate dehydrate, tetramethylammonium hydroxide (TMAH), lead iodide, DMSO, DMF, chlorobenzene and toluene were purchased from Sigma-Aldrich and used as received. [6,6]Phenyl- $\mathrm{C}_{61}$-butyric acid methyl ester $\left(\mathrm{PC}_{61} \mathrm{BM}\right)$ was purchased from American Dyes Source, Inc. $\mathrm{CH}_{3} \mathrm{NH}_{3} \mathrm{I}$ (MAI) was purchased from Shanghai Materwin New Materials Co. Ltd. Poly(bis(4phenyl)(2,4,6-trimethylphenyl)amine) (PTAA) was purchased from Xi'an Polymer Light Technology Corporation. ZnO nanoparticles were synthesized by a sol-gel process using $\mathrm{Zn}$ acetate dehydrate and TMAH, and dispersed in anhydrous isopropanol with a concentration of $20 \mathrm{mg} \mathrm{mL}{ }^{-1} \cdot 39$

\subsection{Device fabrication and testing}

Prior to fabrication, the substrates were cleaned by sonication using detergent, deionized water, acetone, and isopropanol sequentially for every $15 \mathrm{~min}$ followed by $15 \mathrm{~min}$ of ultraviolet ozone (UV-ozone) treatment. The substrates were transferred to a glovebox. PTAA film was fabricated by spin-coating a toluene solution with a concentration of $5 \mathrm{mg} \mathrm{mL} \mathrm{m}^{-1}$ on the ITO substrates in glove-box.

$\mathrm{PbI}_{2}(1 \mathrm{M})$ and DMSO (1 M) were dissolved in DMF under stirring at $70{ }^{\circ} \mathrm{C}$. The solution was then spin coated on the PTAA film at $3000 \mathrm{rpm}$ for $60 \mathrm{~s}$. Then a solution of MAI in 2-propanol (IPA) $\left(50 \mathrm{mg} \mathrm{mL}^{-1}\right)$ was dropped and spin-coated at $3000 \mathrm{rpm}$ for $60 \mathrm{~s}$. Afterwards, the as prepared films were heated at $90{ }^{\circ} \mathrm{C}$ for $15 \mathrm{~min}$. After cooling down, a layer of $\mathrm{PC}_{61} \mathrm{BM}\left(20 \mathrm{mg} \mathrm{mL}^{-1}\right.$ in chlorobenzene) was spin-coated at $2000 \mathrm{rpm}$ for $45 \mathrm{~s}$ for $\mathrm{MAPbI}_{3} / \mathrm{PCBM}$ junction solar cells. While for $\mathrm{MAPbI}_{3} / \mathrm{ZnO}$ junction solar cells $\mathrm{ZnO}$ nanoparticles in isopropanol was spincoated at $4000 \mathrm{rpm}$ for $30 \mathrm{~s}$. Subsequently, samples were loaded into a vacuum deposition chamber (background pressure $\approx 5$ $\times 10^{-4} \mathrm{~Pa}$ ) to deposit a $100 \mathrm{~nm}$ thick $\mathrm{Al}$ cathode with a shadow mask. To specify the illuminated area, we used an aperture with an area of $0.06 \mathrm{~cm}^{2}$, whereas the total device area defined by the overlap of the electrodes was approximately $0.12 \mathrm{~cm}^{2}$.

The $J-V$ characteristics were measured with Keithley 2400 measurement source units with the devices maintained at room temperature in glove-box. The photovoltaic response was measured under a calibrated solar simulator (Enli Technology) at $100 \mathrm{~mW} \mathrm{~cm}^{-2}$, and the light intensity was calibrated with a standard photovoltaic reference cell. The devices were stored in glove-box in dark overnight before measurement. The forward $J-V$ scans were measured from $-0.1 \mathrm{~V}$ to $1.2 \mathrm{~V}$ with a scan rate of $0.05 \mathrm{~V} \mathrm{~s}^{-1}$ and a voltage step of $0.01 \mathrm{~V}$ while the reverse $J-V$ scans were measured from $1.2 \mathrm{~V}$ to $-0.1 \mathrm{~V}$ with a scan rate of $0.05 \mathrm{~V} \mathrm{~s}^{-1}$ and a voltage step of $0.01 \mathrm{~V}$. The EQE spectrum was measured using a QE-R Model of Enli Technology.

\section{Results and discussion}

Inverted perovskite solar cells with the device architecture of ITO/PTAA/MAPbI $3 / \mathrm{PC}_{61} \mathrm{BM}$ or $\mathrm{ZnO} \mathrm{NPs} / \mathrm{Al}$ were fabricated, which were shown in Fig. 1a. Fig. 1b shows the corresponding energy level diagram of the devices. The reported valance band of $\mathrm{ZnO}$ NPs and $\mathrm{PC}_{61} \mathrm{BM}$ are similar with a value of $4.2 \mathrm{eV}$, which is $0.3 \mathrm{eV}$ lower the valance band of $\mathrm{MAPbI}_{3}$, and thus the electrons in perovskite film can transfer to both ETLs and be collected by electrodes. Fig. 2a shows the current-voltage $(J-V)$ characteristics of PSCs based on ZnO NPs and PC $_{61} \mathrm{BM}$ as ETLs under $100 \mathrm{~mW} \mathrm{~cm} \mathrm{~cm}^{-2} \mathrm{AM} 1.5 \mathrm{G}$ solar illumination with reverse and forward scans. The corresponding photovoltaic parameters are summarized in Table 1. The device employing ZnO as ETL exhibits an open-circuit voltage $\left(V_{\mathrm{OC}}\right)$ of $0.98 \mathrm{~V}$, a short-circuit current density $\left(J_{\mathrm{SC}}\right)$ of $12.5 \mathrm{~mA} \mathrm{~cm}^{-2}$, and a fill factor $(\mathrm{FF})$ of 0.64 , yielding a PCE of $8.0 \%$ at reverse scan, and suffers severe hysteresis with a much lower PCE of $6.3 \%\left(V_{\mathrm{OC}}=0.99 \mathrm{~V}, J_{\mathrm{SC}}=\right.$ $12.0 \mathrm{~mA} \mathrm{~cm} \mathrm{~cm}^{-2}$ and $\mathrm{FF}=0.52$ ) at forward scan, respectively. While the device using $\mathrm{PC}_{61} \mathrm{BM}$ as ETL shows a significant improvement in PCE up to $15.0 \%$ at reverse scan with a $V_{\text {OC }}$ of $1.06 \mathrm{~V}$, a $J_{\mathrm{SC}}$ of $19.1 \mathrm{~mA} \mathrm{~cm}{ }^{-2}$ and a $\mathrm{FF}$ of 0.72 , and more importantly, with negligible hysteresis (14.70\% PCE at forward
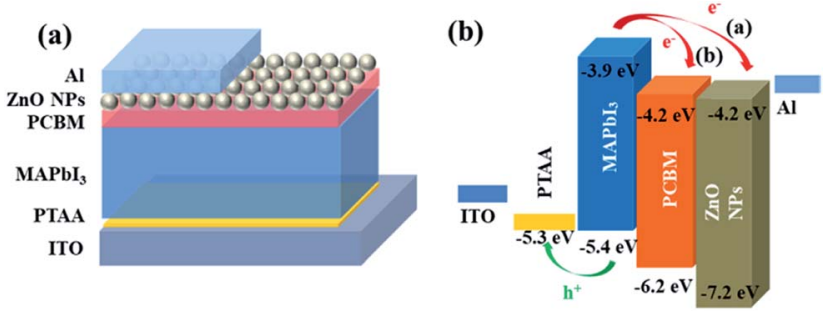

Fig. 1 Schematic illustration of the perovskite solar cell configuration with $\mathrm{PC}_{61} \mathrm{BM} / \mathrm{ZnO}$ NPs as ETL (a). (b) The corresponding energy level diagram of the devices.
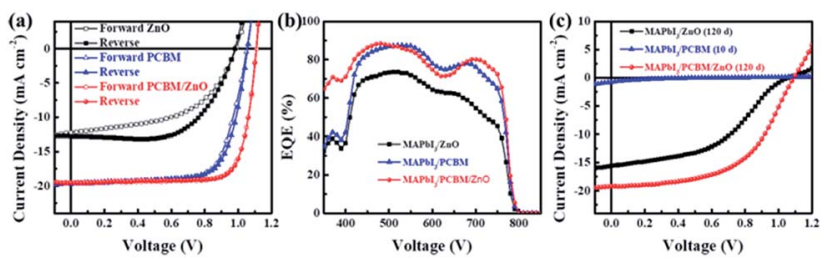

Fig. 2 Current density-voltage $(J-V$ curves (a) and external quantum efficiencies (b) of fresh perovskite solar cells with different ETLs. (c) $J-V$ curves of the devices after storage with a period of 120 days in air with a humidity of $20 \%$. MAPb| ${ }_{3} / \mathrm{PC}_{61} \mathrm{BM}$ heterojunction solar cell was only stored 10 days in the same condition.

Table 1 Device parameters of the PSCs with different ETLs under the illumination of AM $1.5 \mathrm{G}, 100 \mathrm{~mW} \mathrm{~cm}^{-2}$

\begin{tabular}{llllll}
\hline ETL & Scan direction & $V_{\mathrm{OC}}[\mathrm{V}]$ & $J_{\mathrm{SC}}\left[\mathrm{mA} \mathrm{cm}^{-2}\right]$ & FF & PCE $[\%]$ \\
\hline \multirow{2}{*}{ ZnO NPs } & Forward & 0.99 & 12.0 & 0.52 & 6.3 \\
& Reverse & 0.98 & 12.5 & 0.64 & 8.0 \\
PCBM & Forward & 1.05 & 19.2 & 0.71 & 14.7 \\
& Reverse & 1.06 & 19.1 & 0.72 & 15.0 \\
PCBM/ZnO & Forward & 1.11 & 19.5 & 0.78 & 16.9 \\
& Reverse & 1.11 & 19.6 & 0.79 & 17.2
\end{tabular}


scan with a $V_{\mathrm{OC}}$ of $1.05 \mathrm{~V}, \mathrm{a} J_{\mathrm{SC}}$ of $19.2 \mathrm{~mA} \mathrm{~cm}^{-2}$ and a FF of 0.71 ). It exhibits improvement on all three parameters simultaneously compared to those of ZnO NPs based devices. The much enhanced $J_{\mathrm{SC}}$ was also demonstrated by the external quantum efficiency (EQE) spectra shown in Fig. 2b.

We also tested the stability of devices which were stored in air under dark with a humidity of $20 \%$ for 120 days. The corresponding $J-V$ curves were shown in Fig. $2 \mathrm{c}$. We found that the device with ZnO NPs as ETL retained $95 \%$ of the initial PCE, with a $V_{\mathrm{OC}}$ of $1.06 \mathrm{~V}$, a $J_{\mathrm{SC}}$ of $15.6 \mathrm{~mA} \mathrm{~cm} \mathrm{~cm}^{-2}$, a FF of 0.45 and a PCE of $7.6 \%$ after 120 days storage, while the device with only $\mathrm{PC}_{61} \mathrm{BM}$ as ETL almost died only after 10 days, showing a $V_{\mathrm{OC}}$ of $0.56 \mathrm{~V}$, a $J_{\mathrm{SC}}$ of $0.77 \mathrm{~mA} \mathrm{~cm}{ }^{-2}$, a FF of 0.13 and a PCE of $0.06 \%$. The much worse stability was attributed to the poor blocking ability of $\mathrm{PC}_{61} \mathrm{BM}$ against oxygen, water and the electrode. ${ }^{23}$

In order to obtain both high PCE and excellent stability, we also fabricated device with bilayer ETLs in a structure of ITO/ $\mathrm{PTAA} / \mathrm{MAPbI}_{3} / \mathrm{PC}_{61} \mathrm{BM} / \mathrm{ZnO}$ NPs/Al shown in Fig. 1a. The device shows highest $V_{\mathrm{OC}}, J_{\mathrm{SC}}, \mathrm{FF}$ and PCE which ups to $17.2 \%$ at reverse scan with a $V_{\mathrm{OC}}$ of $1.11 \mathrm{~V}, \mathrm{a} J_{\mathrm{SC}}$ of $19.6 \mathrm{~mA} \mathrm{~cm}^{-2}$ and a FF of 0.79 , and also shows negligible hysteresis with a $V_{\mathrm{OC}}$ of $1.11 \mathrm{~V}, \mathrm{a} J_{\mathrm{SC}}$ of $19.5 \mathrm{~mA} \mathrm{~cm}^{-2}$, a FF of 0.78 and a PCE of $16.9 \%$ at forward scan. After stored in air 120 days, the device also shows a decent PCE of $11.4 \%$, with a $V_{\mathrm{OC}}$ of $1.09 \mathrm{~V}$, a $J_{\mathrm{SC}}$ of $19.2 \mathrm{~mA}$ $\mathrm{cm}^{-2}$, a FF of 0.54 , which is $66 \%$ of the initial value. Thus we demonstrated that this type of device show the advantages of the $\mathrm{MAPbI}_{3} / \mathrm{PC}_{61} \mathrm{BM}$ device with high PCE and the $\mathrm{MAPbI}_{3} / \mathrm{ZnO}$ NPs device with good stability.

The effects of different ETLs on the charge extraction and recombination process at perovskite/ETL interface were investigated in details to find out the reasons of different behaviours of corresponding devices. Steady-state photoluminescence (PL) was performed to compare the electron transfer efficiency from perovskite to ETLs. As shown in Fig. 3a, only $54 \%$ of the PL intensity was quenched by depositing ZnO NPs on top, while more than $90 \%$ PL intensity was quenched when $\mathrm{PC}_{61} \mathrm{BM}$ or $\mathrm{PC}_{61} \mathrm{BM} / \mathrm{ZnO}$ NPs were deposited on top of the perovskite layer. This means insufficient charge transfer from perovskite to $\mathrm{ZnO}$ NPs, while electrons in perovskite film can be efficiently transferred to $\mathrm{PC}_{61} \mathrm{BM}$ layer. This was further confirmed by timeresolved PL (TRPL) (Fig. 3b). The TRPL curve was fitted to
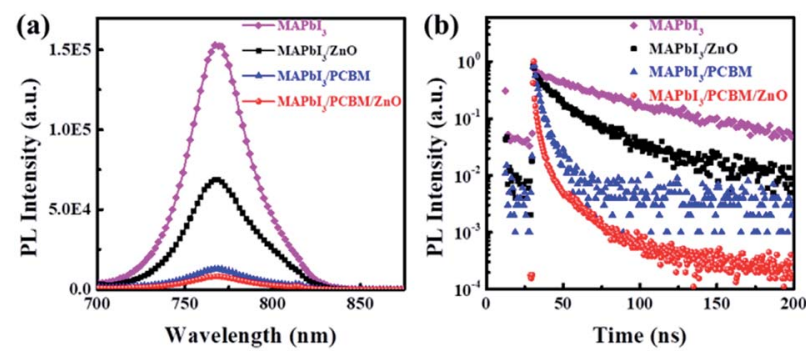

Fig. 3 (a) The steady-state photoluminescence (PL) spectra of $\mathrm{MAPbl}_{3}, \mathrm{MAPb}_{3} / \mathrm{ZnO} \mathrm{NPs}, \mathrm{MAPbl}_{3} / \mathrm{PC}_{61} \mathrm{BM}$ and $\mathrm{MAPbl}_{3} / \mathrm{PC}_{61} \mathrm{BM} / \mathrm{ZnO}$ films. The excitation light was set at $610 \mathrm{~nm}$. (b) Time-resolved PL measurements taken at the peak emission wavelength $(765 \mathrm{~nm})$ of the various perovskite films. A $5 \mathrm{~mW}$ picosecond pulsed diode laser at $638.8 \mathrm{~nm}$ excited on glass side of films. a biexponential equation: $Y=A_{1} \exp \left(-t / \tau_{1}\right)+A_{2} \exp \left(-\mathrm{t} / \tau_{2}\right)$ and the detailed data are shown in Table 2. In the absence of ETL quencher, the pristine perovskite film showed a relatively long PL lifetime of $56.8 \mathrm{~ns}$, while it decreased to 25.6, 5.4 and $5.3 \mathrm{~ns}$ for the $\mathrm{ZnO}$ NPs, $\mathrm{PC}_{61} \mathrm{BM}$ and $\mathrm{PC}_{61} \mathrm{BM} / \mathrm{ZnO}$ NPs-based films, respectively. This implies that faster and more efficient electron extraction was achieved at the perovskite/ $\mathrm{PC}_{61} \mathrm{BM}$ interface. The insufficient charge transfer from perovskite to the ZnO NPs layer compared to $\mathrm{PC}_{61} \mathrm{BM}$ could due to the shallower conduction band and lower electron mobility of ZnO NPs, or the interfacial traps at the perovskite/ZnO NPs interface, ${ }^{23}$ and the worse contact at perovskite/ZnO NPs interface. These could cause charge accumulation at the perovskite/ZnO NPs interface and thus leads to poor performance and severe hysteresis in the corresponding device. ${ }^{23,33,40}$

The recombination kinetics were also studied carefully by measuring $J_{\mathrm{SC}}$ and $V_{\mathrm{OC}}$ at various light intensities (I) from 130 to $2.8 \mathrm{~mW} \mathrm{~cm}^{-2}$ (Fig. $4 \mathrm{a}$ and b). A power law dependence of $J_{\mathrm{SC}}$ upon illumination intensity is generally expressed as $J_{\mathrm{SC}} \propto I^{\alpha}$, where $I$ is the light intensity and $\alpha$ is the exponential factor. At short circuit condition, the bimolecular recombination should be minimum $(\alpha \approx 1)$ for maximum carrier sweep out. Any deviation from $\alpha \approx 1$ implies bimolecular recombination. ${ }^{41-43}$ Fig. 4a shows that $J_{\mathrm{SC}} \propto I^{\alpha}$, where $\alpha=0.96 \pm 0.01$ for the device using ZnO NPs as ETL while $\alpha \approx 1$ for both devices using $\mathrm{PC}_{61} \mathrm{BM}$ or $\mathrm{PC}_{61} \mathrm{BM} / \mathrm{ZnO}$ NPs as ETLs, indicating weak bimolecular recombination at short-circuit condition in the latter two types of devices. ${ }^{43}$ For the $\mathrm{MAPbI}_{3} / \mathrm{ZnO}$ NPs device, the lower $\alpha$ could be attributed to the bimolecular recombination during sweep-out. ${ }^{41,42}$ At open-circuit conditions, the current is zero, all carriers recombine within the cell. Thus,

Table 2 Time-resolved PL data of perovskite films on glass with various ETLS

\begin{tabular}{lrrrrr}
\hline Sample & $\tau_{1}[\mathrm{~ns}]$ & Frac. [\%] & $\tau_{2}[\mathrm{~ns}]$ & Frac. [\%] & Average [ns] \\
\hline $\mathrm{MAPbI}_{3}$ & 10.0 & 4.2 & 58.9 & 95.8 & 56.8 \\
$\mathrm{MAPbI}_{3} / \mathrm{ZnO}$ & 9.3 & 34.0 & 34.0 & 66.0 & 25.6 \\
$\mathrm{MAPbI}_{3} / \mathrm{PCBM}$ & 2.3 & 61.5 & 10.4 & 38.5 & 5.4 \\
$\mathrm{MAPbI}_{3} / \mathrm{PCBM} / \mathrm{ZnO}$ & 1.6 & 68.5 & 13.4 & 31.5 & 5.3
\end{tabular}
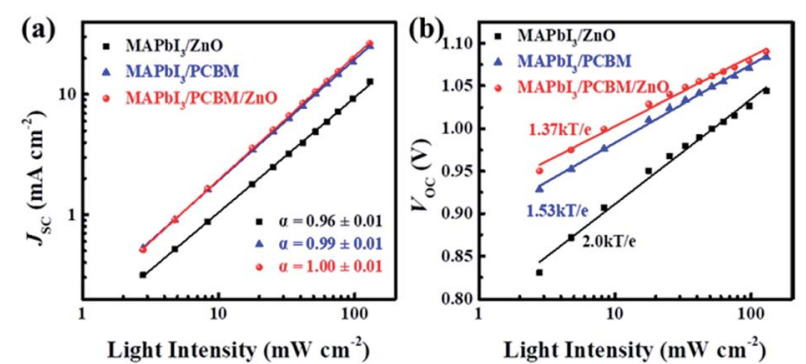

Fig. 4 (a) Measured $J_{\mathrm{SC}}$ of cells with different ETLs plotted against light intensity (symbols) on a logarithmic scale. Fitting a power law (solid lines) to these data yields $\alpha$. (b) Measured $V_{O C}$ of cells with different ETLs plotted against light intensity (symbols), together with linear fits to the data (solid lines). 
recombination studies near open circuit are particularly sensitive to the details of the recombination mechanism. ${ }^{43}$ Fig. $4 \mathrm{~b}$ shows $V_{\mathrm{OC}}$ varies logarithmically $(\ln (I))$ with light intensity. The slopes for device using $\mathrm{ZnO}$ NPs, $\mathrm{PC}_{61} \mathrm{BM}$ and $\mathrm{PC}_{61} \mathrm{BM} / \mathrm{ZnO}$ NPs as ETLs are $2.0 \mathrm{kT} / e, 1.53 \mathrm{kT} / \mathrm{e}$ and $1.37 \mathrm{kT} / \mathrm{e}$ respectively, where $k$ is the Boltzmann constant, $T$ is absolute temperature, and $e$ is elementary charge. In principle, the slope of $V_{\mathrm{OC}}$ versus light intensity will be equal to $k T / e$ if device without trapping of charge carriers or governed by bimolecular recombination, which refers to the recombination of free electrons and holes in the photoactive layer. ${ }^{20,41,43}$ The slope of ZnO NPs based device is $2.0 k T / e$, implying that the monomolecular recombination (Shockley-Read-Hall) recombination through trap states or recombination centers is dominant even at open circuit, which leading to the reduced $V_{\mathrm{OC}}$ and severe hysteresis. ${ }^{36,44}$ In the $\mathrm{MAPbI} / 3 / \mathrm{PC}_{61} \mathrm{BM}$ and $\mathrm{MAPbI} / \mathrm{PC}_{61} \mathrm{BM} / \mathrm{ZnO}$ NPs devices, the slopes indicate that recombination at open circuit is a combination of monomolecular and bimolecular process in both cases and the smaller slopes imply reduced SRH recombination, which contribute to the negligible hysteresis and high device performance. The smallest slope with $\mathrm{PC}_{61} \mathrm{BM} / \mathrm{ZnO}$ NPs bilayer ETLs was also attributed the better contact at $\mathrm{ZnO} / \mathrm{Al}$ interface except for $\mathrm{MAPbI}_{3} / \mathrm{PCBM}$ interface because the robust ZnO NPs film can prevent the Al diffusing into perovskites. ${ }^{23}$ The reduced recombination at both interfaces renders the highest $V_{\mathrm{OC}}$ and performance of this type device.

\section{Conclusions}

We demonstrated that the insufficient charge transfer from $\mathrm{MAPbI}_{3}$ to ZnO NPs and significant interface trap-states lead to the poor performance and severe hysteresis of PSC with $\mathrm{MAPbI}_{3} / \mathrm{ZnO}$ NPs heterojunction, but the device shows super stability in air. While the device based on $\mathrm{MAPbI}_{3} / \mathrm{PC}_{61} \mathrm{BM}$ heterojunction shows high PCE and negligible hysteresis due to the efficient charge transfer from $\mathrm{MAPbI}_{3}$ to $\mathrm{PC}_{61} \mathrm{BM}$ and less recombination at the interface, however the device show very poor stability in air. When $\mathrm{PC}_{61} \mathrm{BM} / \mathrm{ZnO}$ NPs bilayer ETLs were used with a device structure of ITO/PTAA/MAPbI $3 / \mathrm{PC}_{61} \mathrm{BM} / \mathrm{ZnO}$ $\mathrm{NPs} / \mathrm{Al}$, high efficient PSCs with PCE as high as $17.2 \%$ can be achieved with decent stability. Our study also showed the possibility of obtaining highly efficient perovskite/metal oxide NPs heterojunction solar cells by interface engineering without high cost $\mathrm{PC}_{61} \mathrm{BM}$.

\section{Conflicts of interest}

There are no conflicts to declare.

\section{Acknowledgements}

This work was supported by the National Natural Science Foundation of China (No. 51602234) and the National Science Foundation for Post-doctoral Scientists of China (2015M580512).

\section{References}

1 W. Zhang, G. E. Eperon and H. J. Snaith, Nat. Energy, 2016, 1, 16048.

2 C. C. Stoumpos and M. G. Kanatzidis, Adv. Mater., 2016, 28, 5778-5793.

3 N.-G. Park, M. Grätzel, T. Miyasaka, K. Zhu and K. Emery, Nat. Energy, 2016, 1, 16152.

4 B. G. Zhao, L. Zhu, Y. L. Zhao, Y. Yang, J. Song, X. Q. Gu, Z. Xing and Y. H. Qiang, J. Mater. Sci.: Mater. Electron., 2016, 27, 10869-10876.

5 A. Kojima, K. Teshima, Y. Shirai and T. Miyasaka, J. Am. Chem. Soc., 2009, 131, 6050-6051.

6 M. Liu, M. B. Johnston and H. J. Snaith, Nature, 2013, 501, 395-398.

7 F. Z. Huang, Y. Dkhissi, W. C. Huang, M. D. Xiao, I. Benesperi, S. Rubanov, Y. Zhu, X. F. Lin, L. C. Jiang, Y. C. Zhou, A. Gray-Weale, J. Etheridge, C. R. McNeill, R. A. Caruso, U. Bach, L. Spiccia and Y. B. Cheng, Nano Energy, 2014, 10, 10-18.

8 N. J. Jeon, J. H. Noh, Y. C. Kim, W. S. Yang, S. Ryu and S. I. Seok, Nat. Mater., 2014, 13, 897-903.

9 M. Xiao, F. Huang, W. Huang, Y. Dkhissi, Y. Zhu, J. Etheridge, A. Gray-Weale, U. Bach, Y. B. Cheng and L. Spiccia, Angew. Chem., Int. Ed., 2014, 53, 9898-9903.

10 X. Li, D. Bi, C. Yi, J. D. Decoppet, J. Luo, S. M. Zakeeruddin, A. Hagfeldt and M. Gratzel, Science, 2016, 353, 58-62.

11 M. Saliba, T. Matsui, K. Domanski, J.-Y. Seo, A. Ummadisingu, S. M. Zakeeruddin, J.-P. Correa-Baena, W. R. Tress, A. Abate, A. Hagfeldt and M. Grätzel, Science, 2016, 354, 206-209.

12 D. P. McMeekin, G. Sadoughi, W. Rehman, G. E. Eperon, M. Saliba, M. T. Hörantner, A. Haghighirad, N. Sakai, L. Korte, B. Rech, M. B. Johnston, L. M. Herz and H. J. Snaith, Science, 2016, 351, 151-155.

13 N. J. Jeon, J. H. Noh, W. S. Yang, Y. C. Kim, S. Ryu, J. Seo and S. I. Seok, Nature, 2015, 517, 476-480.

14 T. Jesper Jacobsson, J.-P. Correa-Baena, M. Pazoki, M. Saliba, K. Schenk, M. Gratzel and A. Hagfeldt, Energy Environ. Sci., 2016, 9, 1706-1724.

15 T. Ye, S.-L. Lim, X. Li, M. Petrović, X. Wang, C. Jiang, W.-P. Goh, C. Vijila and S. Ramakrishna, Sol. Energy Mater. Sol. Cells, 2018, 175, 111-117.

16 H. J. Snaith, J. Phys. Chem. Lett., 2013, 4, 3623-3630. 17 S. Gamliel and L. Etgar, RSC Adv., 2014, 4, 29012-29021. 18 M. Saliba, S. Orlandi, T. Matsui, S. Aghazada, M. Cavazzini, J. P. Correa-Baena, P. Gao, R. Scopelliti, E. Mosconi, K. H. Dahmen, F. De Angelis, A. Abate, A. Hagfeldt, G. Pozzi, M. Graetzel and M. K. Nazeeruddin, Nat. Energy, 2016, 1, 15017. 19 Z. Zhu, J. Q. Xu, C. C. Chueh, H. Liu, Z. Li, X. Li, H. Chen and A. K. Jen, Adv. Mater., 2016, 28, 10786-10793.

20 H. Zhang, H. Wang, W. Chen and A. K. Jen, Adv. Mater., 2017, 29, 1604984.

21 W. Chen, Y. Wu, Y. Yue, J. Liu, W. Zhang, X. Yang, H. Chen, E. Bi, I. Ashraful, M. Gratzel and L. Han, Science, 2015, 350, 944-948. 
22 https://www.nrel.gov/pv/assets/images/efficiency-chart.png.

23 J. You, L. Meng, T. B. Song, T. F. Guo, Y. M. Yang, W. H. Chang, Z. Hong, H. Chen, H. Zhou, Q. Chen, Y. Liu, N. De Marco and Y. Yang, Nat. Nanotechnol., 2016, 11, 75-81. 24 D. Wang, M. Wright, N. K. Elumalai and A. Uddin, Sol. Energy Mater. Sol. Cells, 2016, 147, 255-275.

25 D. Li, P. Liao, X. Shai, W. Huang, S. Liu, H. Li, Y. Shen and M. Wang, RSC Adv., 2016, 6, 89356-89366.

26 H. Choi, S. Park, M. S. Kang and J. Ko, Chem. Commun., 2015, 51, 15506-15509.

27 S. Ye, W. Sun, Y. Li, W. Yan, H. Peng, Z. Bian, Z. Liu and C. Huang, Nano Lett., 2015, 15, 3723-3728.

28 J. A. Christians, R. C. M. Fung and P. V. Kamat, J. Am. Chem. Soc., 2014, 136, 758-764.

29 J. W. Jung, C.-C. Chueh and A. K. Y. Jen, Adv. Mater., 2015, 27, 7874-7880.

30 S. Weber, T. Rath, J. Mangalam, B. Kunert, A. M. Coclite, M. Bauch, T. Dimopoulos and G. Trimmel, J. Mater. Sci.: Mater. Electron., 2018, 29, 1847-1855.

31 D. Liu and T. L. Kelly, Nat. Photonics, 2014, 8, 133-138.

32 J. Duan, Q. Xiong, H. Wang, J. Zhang and J. Hu, J. Mater. Sci.: Mater. Electron., 2017, 28, 60-66.

33 Q. Jiang, L. Zhang, H. Wang, X. Yang, J. Meng, H. Liu, Z. Yin, J. Wu, X. Zhang and J. You, Nat. Energy, 2016, 2, 16177.
34 Y. Li, J. Zhu, Y. Huang, F. Liu, M. Lv, S. Chen, L. Hu, J. Tang, J. Yao and S. Dai, RSC Adv., 2015, 5, 28424-28429.

35 D. Bi, C. Yi, J. Luo, J.-D. Décoppet, F. Zhang, S. M. Zakeeruddin, X. Li, A. Hagfeldt and M. Grätzel, Nat. Energy, 2016, 1, 16142.

36 C. Bi, Q. Wang, Y. Shao, Y. Yuan, Z. Xiao and J. Huang, Nat. Commun., 2015, 6, 7747.

37 Y. Shao, Y. Yuan and J. Huang, Nat. Energy, 2016, 1, 15001.

38 W. Fu, J. Yan, Z. Zhang, T. Ye, Y. Liu, J. Wu, J. Yao, C.-Z. Li, H. Li and H. Chen, Sol. Energy Mater. Sol. Cells, 2016, 155, 331-340.

39 L. Qian, J. Yang, R. Zhou, A. Tang, Y. Zheng, T.-K. Tseng, D. Bera, J. Xue and P. H. Holloway, J. Mater. Chem., 2011, 21, 3814-3817.

40 H. Li, W. Shi, W. Huang, E. P. Yao, J. Han, Z. Chen, S. Liu, Y. Shen, M. Wang and Y. Yang, Nano Lett., 2017, 17, 23282335.

41 A. K. Kyaw, D. H. Wang, D. Wynands, J. Zhang, T. Q. Nguyen, G. C. Bazan and A. J. Heeger, Nano Lett., 2013, 13, 3796-3801. 42 V. Gupta, A. K. Kyaw, D. H. Wang, S. Chand, G. C. Bazan and A. J. Heeger, Sci. Rep., 2013, 3, 1965.

43 S. R. Cowan, A. Roy and A. J. Heeger, Phys. Rev. B: Condens. Matter Mater. Phys., 2010, 82, 245207.

44 Y. Shao, Z. Xiao, C. Bi, Y. Yuan and J. Huang, Nat. Commun., 2014, 5, 5784 . 